in vivo $34: 2527-2541(2020)$

doi:10.21873/invivo.12070

\title{
Lingual Mandibular Bone Depression
}

\author{
REINHARD E. FRIEDRICH ${ }^{1}$, EVGENY BARSUKOV ${ }^{2}$, FELIX K. KOHLRUSCH ${ }^{1}$, JOZEF ZUSTIN ${ }^{3}$, \\ CHRISTIAN HAGEL ${ }^{4}$, ULRIKE SPETH ${ }^{1}$, TOBIAS VOLLKOMMER ${ }^{1}$ and MARTIN GOSAU ${ }^{1}$ \\ ${ }^{1}$ Department of Oral and Craniomaxillofacial Surgery, \\ Eppendorf University Hospital, University of Hamburg, Hamburg, Germany; \\ ${ }^{2}$ Department of Oral and Craniomaxillofacial Surgery, \\ Asklepios Klinikum Nord, Hamburg, Germany; \\ ${ }^{3}$ Institute of Pathology, Regensburg, Germany; \\ ${ }^{4}$ Institute of Neuropathology, Eppendorf University Hospital, \\ University of Hamburg, Hamburg, Germany
}

\begin{abstract}
Background/Aim: In the area of the jaw angle, osteolytic lesions can occur, the differential diagnosis of which can be difficult and require very different therapeutic measures. One of these lesions is lingual mandibular bone depression (LMBD). The aim of this study was to present the characteristics of the lesion in a group of LMBD patients and to differentiate it from other lesions. Patients and Methods: Radiological images of 21 patients with $L M B D$ were examined. Results: The majority of $L M B D$ s were located in the jaw angle. On cross-sectional images, the lesion could be distinguished from salivary tissue $(n=2)$. One case of $L M B D$ had an impact on the course of the fracture line in the mandibular trauma. Conclusion: LMBD is a developmental disorder of the mandible and only rarely of pathological importance. Imaging the lesion with cross-sectional images is preferable to using plain $X$-ray projections. In some cases, surgical exploration is essential for diagnosis.
\end{abstract}

In the area of the jaw angle, numerous osteolytic lesions can arise with very different biological characteristics requiring different diagnostic and therapeutic measures (1-11). One of these lesions is a distinct osseous cavity of unknown origin arising on the lingual site of the bone, just anterior to the

This article is freely accessible online.

Correspondence to: Reinhard E. Friedrich, MD, DMD, Ph.D., Department of Oral and Cranio-Maxillofacial Surgery, Eppendorf University Hospital, University of Hamburg, Martinist. 52, D-20246 Hamburg, Germany. Tel: +49 40741053259, e-mail: rfriedrich@uke.de

Key Words: Mandible, lingual mandibular bone depression, Stafne's bone cavity, fracture, anatomy, vascularization, imaging, differential diagnosis, bone tumor. mandibular angle, near the inferior border and below the molar teeth. The lesion was originally described by Stafne on plain radiographs (12) and has since been associated with his name (13-15). By far the largest number of cases are one-sided $(12,16)$, mainly affect males $(12,17)$ and people in adulthood, especially in the 5th decade of life or older (16). Many authors describe a lesion that is limited to the lower border of the mandible, so that the mandibular canal forms the upper boundary of the lesion $(12,16,18)$. Furthermore, it is assumed that the lesion has a self-limiting growth capacity, which is limited to a size of a few centimeters in the anterior-posterior direction (19). However, exceptions to the lesion's definitions have been described, both in terms of topography (20-24), number of cavities $(25)$, size and shape $(26,27)$, relationship to the nerve canal as the cranial border of lesion (28) and capability of the lesion to displace the canal (29). On X-rays, the outline of the lesion can show a radiopaque margin and thus be assessed as 'sclerosed' (30), but this finding is not mandatory (31). Marginal sclerosis is interpreted as the consequence of bone remodelling following an undetermined bone-dissolving external pressure $(16,32)$. The circular bone impression is usually completely surrounded by bone. However, the osseous caudal delimitation of the lesion can be absent, especially in the case of larger lesions, giving the impression of an extensive osteolytic tumor (33). An essential part of the lesion's definition is the lingual depression of bone, which means that there must be a shell-like cavity on the lingual side of the mandible in order to make the diagnosis $(15,16)$. This characteristic of the lesion often cannot be reliably described on plain radiography $(2,3,33)$.

Given the multitude of different descriptions of lingual defects of the mandible, which can also arise outside the jaw angle region, "lingual mandibular bone depression" (LMBD) was proposed as an umbrella term for the benign bone lesions $(14,16)$. 

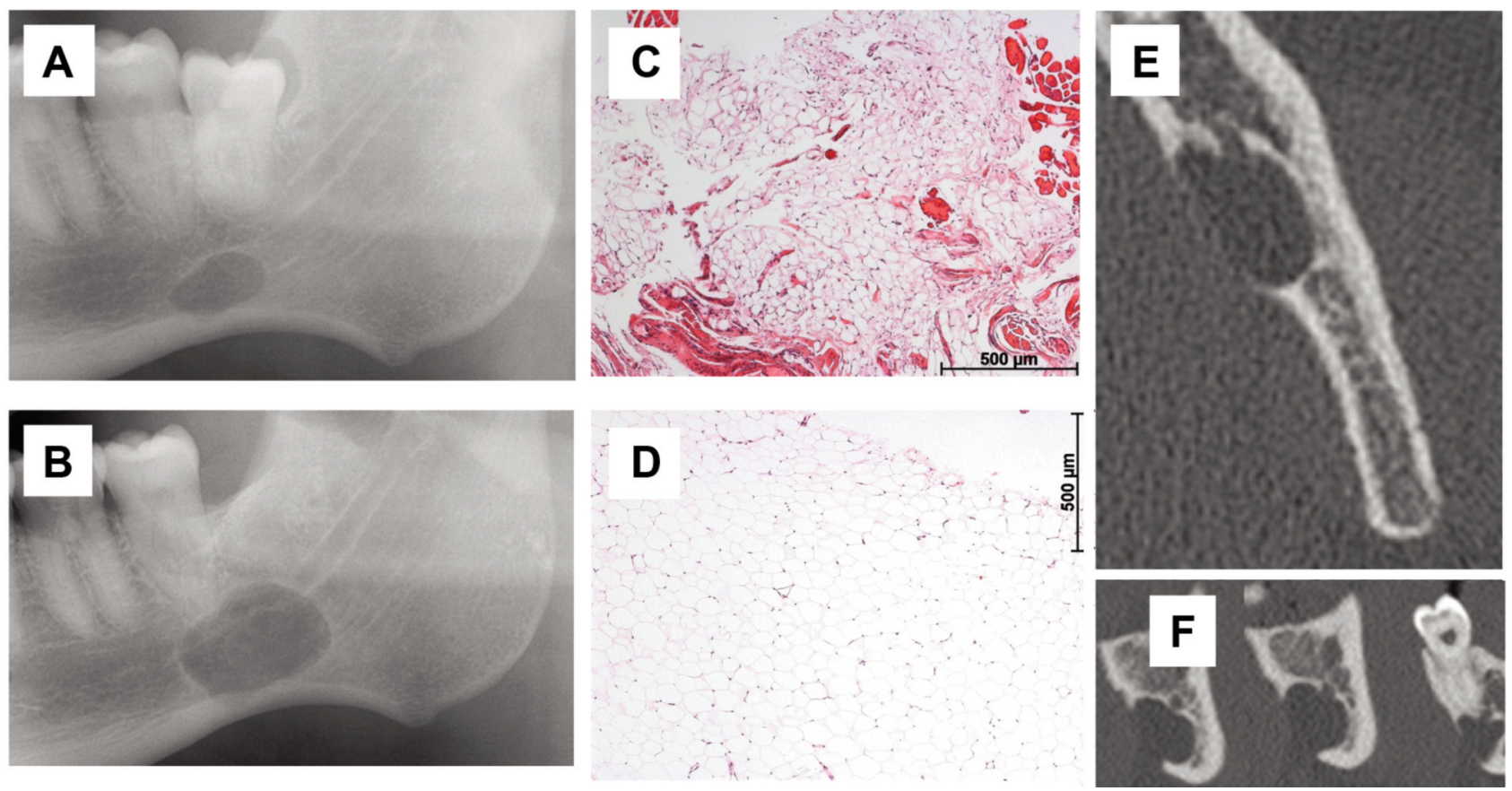

Figure 1. Lingual mandibular bone depression (LMBD) of the left side. (A and B): Comparison of the growing area of the lesions at the time of first diagnosis $(A)$ and 5 years later $(B)$ on two orthopantomograms $(O P G) .(C$ and $D)$ : Histological findings of the tissue samples from the lesion show in $(C)$ fibro-lipomatous soft tissue without inflammatory changes and several muscle cells within the tissues removed from the bone lesion. Epithelial structures are not present. (D) Univacuolar large fat cells without atypia are shown. No epithelial structures could be found on serial sections of the tissues removed from the Stafne's bone cavity. There are no signs of inflammatory or neoplastic changes of fat tissue. The interruption of the nerve canal is visible in cone beam tomograms $(E, F)$. The caudal boundary of the channel is missing in sections in the area of the LMBD $(F)$. This finding cannot be made on the $O P G(B)$.

The historical development of dental X-ray equipment is reflected in LMBD imaging. The majority of studies on the prevalence of LMBD were carried out on orthopantomograms (OPG). The larger number of recent studies on this topic is probably due to the fact that cross-sectional images, especially cone beam computed tomography (CBCT), which has been used widely, provide a much more detailed picture of the internal structure of the bone and the bone surface (34). The aim of this investigation was to contribute to the characterization of the phenotype of the entity, discuss important differential diagnoses and the limits of the radiological definition of a skeletal lesion, to update the hypotheses on pathogenesis and the presentation of surgical consequences in individual cases.

\section{Patients and Methods}

X-rays and MRI of 21 patients (19 male and 2 female) with LMBD were examined. Mean age at time of diagnosis of posterior LMBD $(n=19)$ was 54.95 years $(y s)$, range $=36-82$ ys [anterior LMBD $(n=1)$ : 11 ys; ramus ( $n=1): 82$ ys]. All cases were coincidental findings on OPGs that had been made for various reasons during dental or surgical examinations. The patients were then referred to the Outpatient Department of the Oral and Craniomaxillofacial Clinic, Eppendorf University Hospital, for further diagnosis and therapy. Patients with
LMBD that were previously reported in a study on the prevalence of the condition (17) and as case reports describing extraordinarily large osteolysis (33) and LMBD in a tumor suppressor gene disease (35) were excluded from the present cohort. This report contains the followup of a rare case of anterior LMBD (24). Radiological examinations using OPG $(\mathrm{n}=18)$, CBCT $(\mathrm{n}=10)$, and magnetic resonance images (MRI) $(n=3)$ were available for analysis. In one case, surgical exploration of the lesion was performed because there was significant growth of the lesion comparing two OPGs 5 years apart.

Furthermore, additional 4 cases were included in this descriptive analysis, which apparently had no LMBD. These illustrative examples were chosen to define some difficulties of differential diagnosis using radiological examinations to define LMBD and to bring back into the discussion previous suggestions to explain the entity's pathogenesis.

The results refer to cases with accepted LMBD. The other cases used for differential diagnosis are explained in the discussion.

\section{Results}

Representative pathological findings of LMBD are illustrated in detail in Figures 1 to 4 and summarized in Table I.

Localization. Eighteen lesions were defined as posterior LMBD, one case in the dorsal ramus, one at the corpus and one was defined as anterior LMBD (18/1/1/1, respectively). 

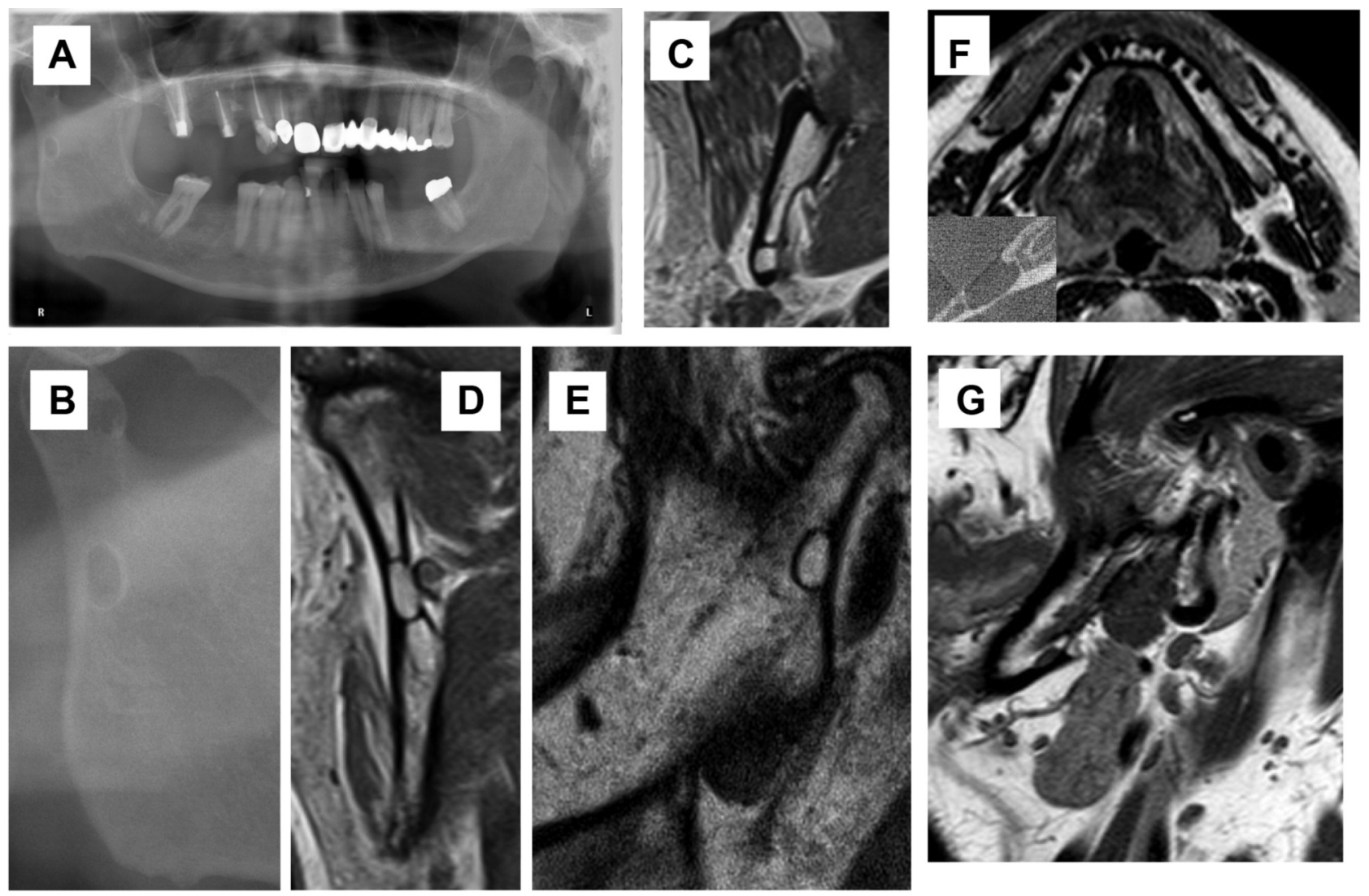

Figure 2. Orthopantomogram (OPG) (A-B) and magnetic resonance imaging (MRI) (C-E) of a mandibular depression of the right mandibular ramus $(A-E)$. The second case is a lingual mandibular bone depression (LMBD) located in the left side of the mandibular body (F-G). A: The oval radiotranslucent lesion lies below the condyle in the dorsal area of the ramus (A: orthopantomogram, $B$ detail of A showing sclerosed margin of the bone lesion). This is the typical location of the rare mandibular depression in the mandibular ramus. MRI shows a sharply defined intraosseous lesion ( $D=$ coronal section; $C=$ axial section, anterior to the top; $E=$ sagittal section). The recorded resonance of the lesion corresponds to the reaction of adipose tissue or lymphoid tissue. F-G: In the MRI of the second case, there is a hyperintense soft tissue structure inside the osseous lesion and distinct to the bone and floor of the mouth ( $F=$ axial section, insert: cone beam computed tomogram of the lesion, axial section, cropped image). G: The buccal cortex is intact at the site of LMBD (confirmed on CBCT, see insert in F). The lesion extends to the floor of the mouth as far as the salivary gland ( $G=$ sagittal section). The signalling of the lesion is easy to differentiate from the salivary gland.

Laterality. All findings occurred as single lesions (right: 8, left: 12 cases), except for an extensive anterior LMBD, which was bilateral.

Dentition. The majority of the patients with LMBD were toothed. Only in one case with posterior LMBD the large size lesion reached a tooth root (molar) which was revealed on sectional images. Imaging of the case with anterior LMBD revealed exposed, undamaged root tips in the cavity (Figure 4). This loss of periapical bone had not been described on the previous recordings (24).

Marginal sclerosis of lesion. A sclerosis of the bone defect was visible in most of the cases $(n=18)$. The finding was missing in 2 patients and in another patient an arch-shaped small radiopaque line surrounding the lesion was only visible in a second follow-up plain radiograph. In cases with sectional images of the mandible, cases with cortical bonetype definition of the lesion's margin do not necessarily show this finding in every image.

Relationship of LMBD to inferior mandibular border. Approximately half of the lesions were so small in size that a line of cancellous bone was visible between the LMBD and the radiopaque zone defining the basal cortex. None of the lesions eroded the basal cortex in such a way that the line-shaped lower edge of the bone was suspected to be interrupted in the $\mathrm{X}$-ray image. In one case, the growth of the lesion could be followed up to the final superimposition with the basal cortex.

Relationship of LMBD to nerve canal. The majority of cases showed superimposition of the lesion with the nerve canal. 

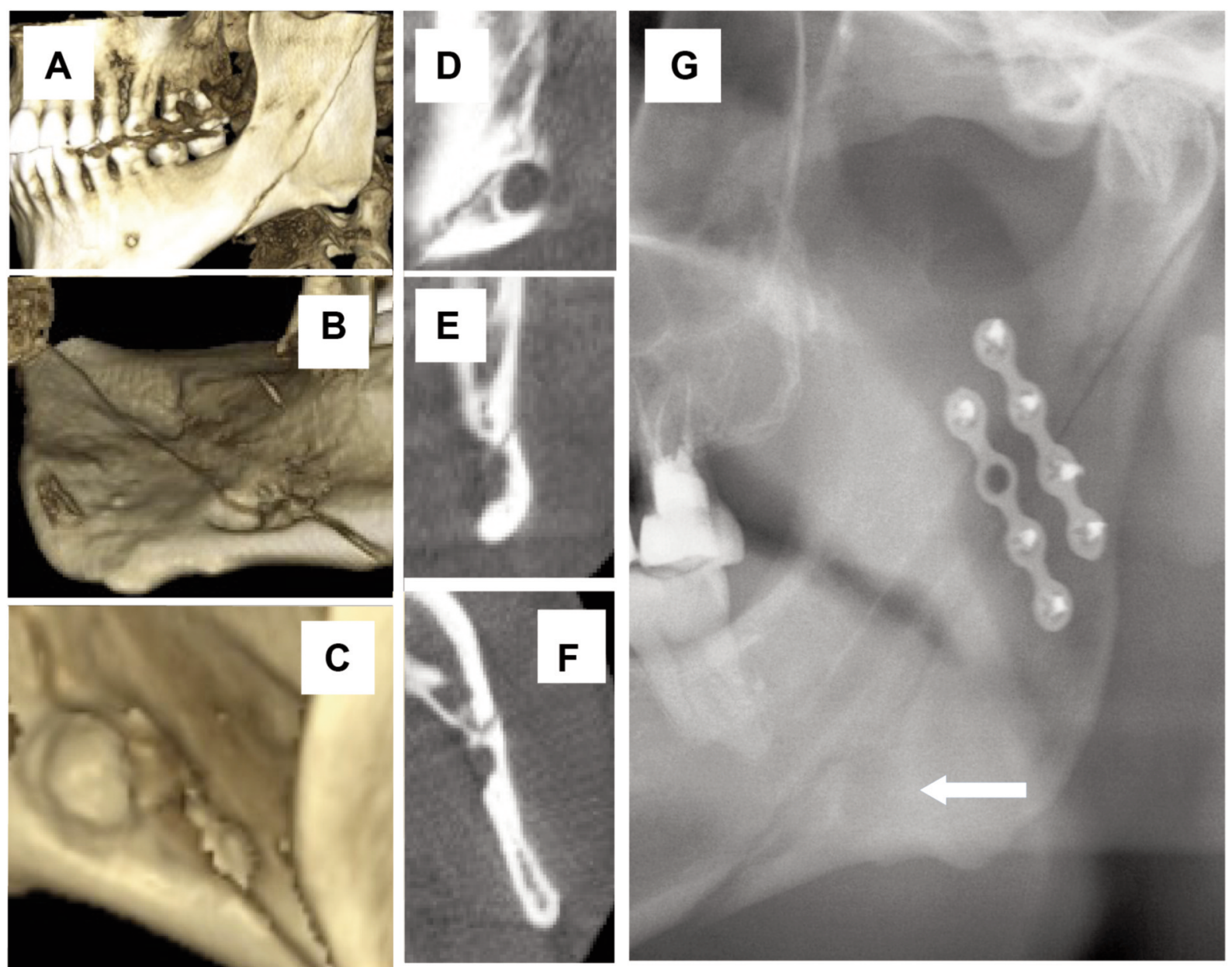

Figure 3. Cone Beam Computed Tomography $(C B C T)(A-F)$ and orthopantomogram $(G)$ of mandibular fracture and lingual mandibular bone depression $(L M B D)$. The fracture begins in the posterior ramus and extends caudally to the base of the lower jaw in the area of the third molar. The vestibular surface of the lower jaw is not bulged in the area of suspected LMBD. The lingual course of the fracture shows the slight kink at the upper edge of $L M B D(B$ and $C)$. The fracture line, that only marginally affects $L M B D$, is evident in the detailed CBCT images (sections: D=sagittal, $E=$ coronal, $F=$ axial). The lesion is barely visible in the directly postoperative OPG (arrow). In the OPG, the LMBD has no sclerosed margin.

However, most of the findings had been obtained using OPG. Here, the assessment of the course of the nerve canal in relation to the lesion could not be ensured by means of the summation of several hard tissue structures on a plain $\mathrm{x}$ ray. However, the nerve canal, especially the cranial border, was visible in most cases $(n=16$, not visible $n=2, O P G)$ (Figure 1). Both, the lesion of the ramus (Figure 2) and the cup-like indentation of the posterior edge of the mandible had no relation to the nerve canal or foramen. The anterior LMBD also had no influence on the mandibular canal. The variable relationship between the nerve canal and the cavity on $\mathrm{CBCT}$ were observed in a single case (Figure 1).

Bucco-lingual extension. Bucco-lingual extension was estimated on CBCT ( $\mathrm{n}=10)$ according to published criteria
(15) (Figure 5). The lesions were limited to the cancellous bone of the lower jaw in 5 cases (Type I) and reached the buccal cortex in 5 cases (Type II). No buccal protrusion of the bone was observed (15).

Follow up control. Radiological follow-ups were assessed in 5 of 19 cases (38.3\%). Enlargement of the cavity was demonstrated in 4 out of 5 cases. However, in four cases with distal LMBD, the previous X-ray examinations were specifically requested in order to prove progression of the lesion. In the case of anterior LMBD, there was a follow-up because the finding was already known (24). Increase in the size of the lesions was demonstrated for a time interval of 1 to 8 years (Figures 1 and 4 ). When evaluating growth, a distinction must be made between the location of the lesion 

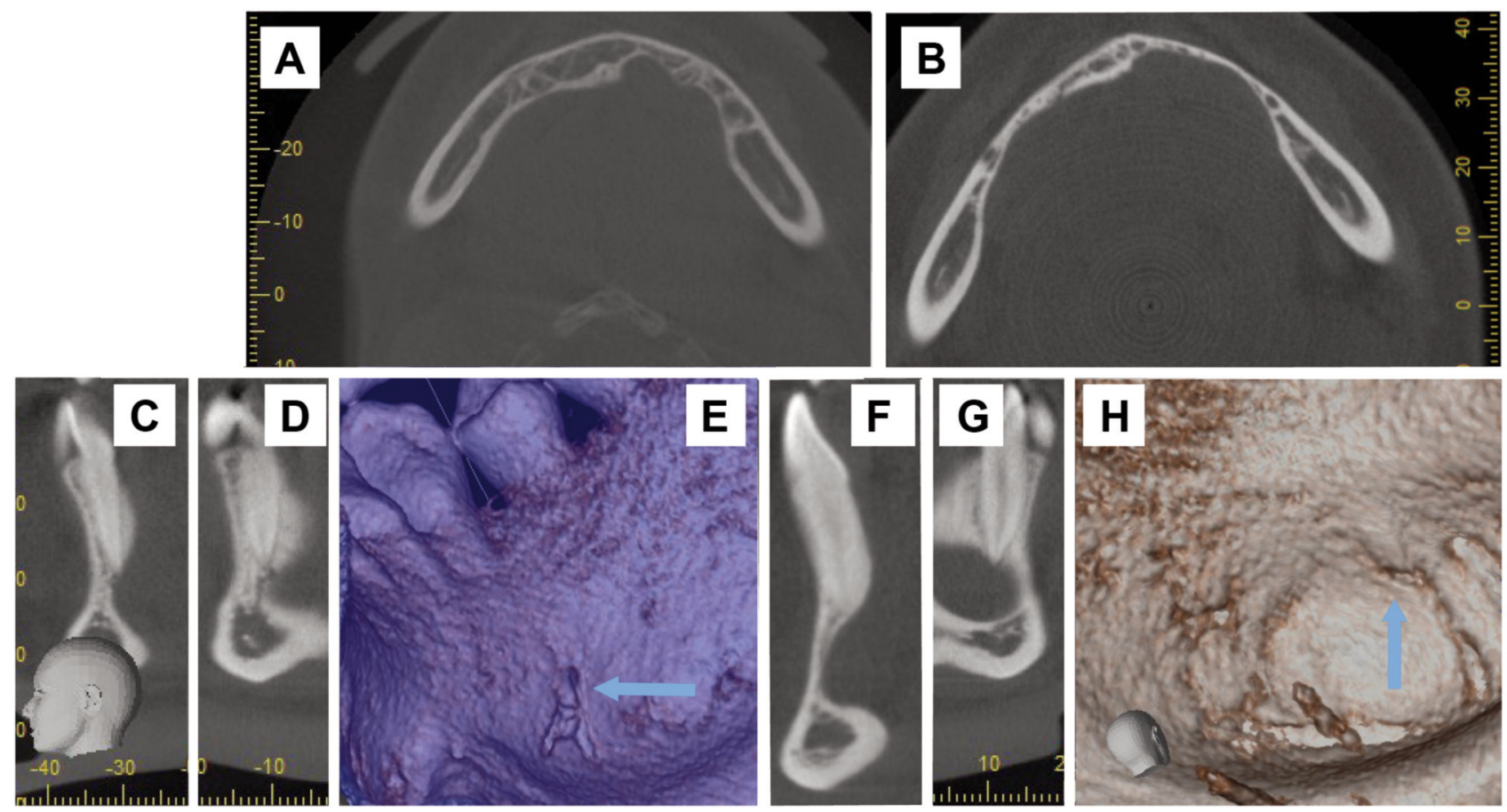

Figure 4. Cone beam computed tomography of anterior lingual mandibular bone depression (LMBD). A. Axial section of anterior mandible at the age of 11 years: asymmetrical, bilateral anterior LMBD. The lingual cortex delimits the bone in the area of the cavity. Cancellous bone is distinguishable. B: Eight years later, the cancellous bone in the left area of the lesion has almost completely disappeared. The spine-like bone brace is completely resorbed in the grown lower jaw (A and B: axial sections). Figures $C$-E show the apical region of the left canine. The root tip protrudes into the cavity ( $C=$ sagittal, $D=$ coronal projection). The exposed root apex can be clearly seen on the reconstructed bone surface (E) (arrow). Figures $F-H$ show the apical region of the right canine. The root tip protrudes into the cavity ( $F=$ sagittal, $G=$ coronal projection). The exposed root apex can be clearly seen on the reconstructed bone surface $(H)$ (arrow).

and the relative growth of the lesion in relation to the imaging quality of the radiological device. For example, LMBD representation on OPG depends on the relationship between the lesion and the focal trough of the radiological device in the single case. In contrast, the growth of the anterior LMBD can be clearly shown comparing CBCT made on the same device in multiple dimensions performed 8 years apart (Figure 4A and B). The extent and early progression of the lesion in the anterior LMBD could not be assessed on previous OPGs (24). What is striking about the current extent of the finding in anterior LMBD is the bilateral enlargement of the bone depression in sagittal and transverse directions, so that in some areas the cancellous bone is narrowed to a barely visible layer. The spina that is still visible in the twelve-year-old patient has since been absorbed. Fully formed tooth roots protrude into this cavity (the teeth are firmly seated in the alveoli and react promptly to adequate cold stimuli) (Figure 4C-H).

Content of lesions. In one case, the lesion was surgically explored. The defect contained only fat and muscle tissue. In one case (Figure 1), the defect was filled in with hyperintense, solid tissue that could be traced in continuity to the immediately adjacent floor of the mouth. There was no direct connection to the salivary gland. The case with anterior LMBD showed replacement of the formerly bony area by normal salivary gland tissue (Figure 4).

Trauma. One patient had a fracture of the mandibular ramus due to trauma. The fracture line ran diagonally through the ramus and met the ipsilateral lingual mandibular depression. The LMBD was located below the nerve canal. The threedimensional representation showed the rounded, domeshaped lesion, which was undoubtedly not caused by the trauma. The linear fracture line should have divided the lesion centrally, however, at the contact point to the LMBD, the fracture line deviated slightly and continued through it only marginally. The X-ray check-up (OPG) after surgical treatment hardly showed the LMBD (Figure 3).

\section{Discussion}

This study shows that the main manifestation of LMBD lies in the area of the jaw angle and thus confirms the 
Table I. Radiological findings of lingual mandibular bone depression (LMBD). M, Male; F, female; OPG, orthopantomogram; CBCT, cone beam computed tomogram; CT, computed tomogram; MRI, magnetic resonance image; +, findings are confirmed; -, findings are missing.

\begin{tabular}{|c|c|c|c|c|c|c|c|c|c|c|}
\hline ID & Gender & $\mathrm{Age}^{1}$ & Localization & $\begin{array}{l}\text { Dentulous } \\
\text { in LMBD } \\
\text { region }\end{array}$ & $\begin{array}{cc}\text { Imaging } & S \\
\text { technique(s) } & b\end{array}$ & $\begin{array}{l}\text { Sclerotic } \\
\text { border of } \\
\text { lesion }\end{array}$ & $\begin{array}{l}\text { Relationship } \\
\text { of LMBD to } \\
\text { inferior border } \\
\text { of mandible } 2\end{array}$ & $\begin{array}{l}\text { Relationship } \\
\text { of LMBD to } \\
\text { mandibular } \\
\text { canal }^{3}\end{array}$ & $\begin{array}{l}\text { Growth } \\
\text { characteristics } \\
\text { of LMBD } \\
\text { (years) }\end{array}$ & Remarks \\
\hline 1 & M & $33 / 38$ & Angle, left & $+/+$ & OPG, CBCT & $+/+$ & $1 / 1$ & $1 / 2$ & $\begin{array}{l}\text { Increase in } \\
\text { size (5ys) }\end{array}$ & $\begin{array}{l}\text { In axial CBCT, the lesion } \\
\text { is more hypodense than } \\
\text { the adjacent mouth floor }\end{array}$ \\
\hline 2 & M & 49 & Angle, left & + & OPG & - & 0 & 0 & & \\
\hline 3 & M & 45 & Angle, right & + & OPG & + & 1 & 1 & & \\
\hline 4 & M & $42 / 42$ & Angle, right & $+/+$ & $\begin{array}{l}\text { OPG, Occlusal } \\
\text { view }\end{array}$ & $-1+$ & $0 / 0$ & $1 / 1$ & $\begin{array}{c}\text { Increase } \\
\text { in size }(1 \mathrm{y})\end{array}$ & \\
\hline 5 & M & 79 & Angle, right & + & $\mathrm{CBCT}$ & + & 0 & 1 & & $\begin{array}{l}\text { In axial CBCT, the lesion } \\
\text { is more hypodense than } \\
\text { the adjacent mouth floor }\end{array}$ \\
\hline 6 & M & 36 & Angle, left & + & $\mathrm{CBCT}$ & + & 0 & 1 & & $\begin{array}{l}\text { In axial CBCT, the lesion } \\
\text { is more hypodense than } \\
\text { the adjacent mouth floor }\end{array}$ \\
\hline 7 & M & 49 & Angle, left & + & OPG, CBCT & + & 0 & 0 & & $\begin{array}{l}\text { Fracture runs laterally } \\
\text { through the cavity }\end{array}$ \\
\hline 8 & M & 49 & Angle, left & + & OPG, CBCT, MRI & I + & 1 & 1 & & $\begin{array}{l}\text { In axial CBCT, the lesion } \\
\text { is more hypodense than } \\
\text { the adjacent mouth floor } \\
\text { On MRI, the hyperdense } \\
\text { lesion is continuous with } \\
\text { lingual soft tissue }\end{array}$ \\
\hline 9 & M & 47 & Angle, left & + & OPG, CBCT & + & 0 & 1 & & $\begin{array}{l}\text { In axial CBCT, the lesion } \\
\text { is more hypodense than } \\
\text { the adjacent mouth floor }\end{array}$ \\
\hline 10 & M & $47 / 50 / 55$ & Angle, right & $+/+/+$ & OPG, CBCT & + & $0 / 0 / 1$ & $0 / 0 / 1$ & $\begin{array}{l}\text { Increase in } \\
\text { size (8ys) }\end{array}$ & $\begin{array}{l}\text { In axial CBCT, the lesion } \\
\text { is more hypodense than } \\
\text { the adjacent mouth floor }\end{array}$ \\
\hline 11 & M & $61 / 63$ & Angle, right & $+/+$ & OPG & + & $1 / 1$ & $1 / 1$ & Stable (2ys) & \\
\hline 12 & M & 61 & Angle, left & + & OPG & + & 0 & 1 & & \\
\hline 13 & M & 64 & Angle, left & + & OPG & + & 2 & 2 & & \\
\hline 14 & M & 80 & Angle, left & - & OPG & + & 1 & 1 & & \\
\hline 15 & M & 54 & Angle, left & + & CBCT & + & 1 & 1 & & $\begin{array}{l}\text { In axial CBCT, the lesion } \\
\text { is more hypodense than } \\
\text { the adjacent mouth floor }\end{array}$ \\
\hline 16 & M & 60 & Angle, left & - & OPG & - & 1 & 1 & & \\
\hline 17 & $\mathrm{~F}$ & 72 & Angle, right & - & OPG & + & 2 & 0 & & \\
\hline 18 & M & 42 & Angle, right & + & $\begin{array}{l}\text { OPG, skull } \\
\text { radiographs }\end{array}$ & + & 1 & 1 & & $\begin{array}{l}\text { Incidental finding on skull } \\
\text { radiographs for fracture } \\
\text { diagnostics: Left } \\
\text { mandibular angle fracture } \\
\text { following cystectomy } \\
\text { (extensive keratocyst) }\end{array}$ \\
\hline 19 & M & 47 & Corpus, left & + & $\begin{array}{l}\text { OPG, CBCT, } \\
\text { whole body CT }\end{array}$ & - & 2 & 2 & & $\begin{array}{l}\text { Incidental finding on whole } \\
\text { body CT performed for } \\
\text { tumor staging }\end{array}$ \\
\hline 20 & M & 82 & $\begin{array}{l}\text { Ramus, right, } \\
\text { dorsal-cranial }\end{array}$ & + & OPG, MRI & + & 0 & 0 & & $\begin{array}{c}\text { On MRI, the lesion is } \\
\text { isointense with adipose } \\
\text { tissue }\end{array}$ \\
\hline 21 & $\mathrm{~F}$ & 19 & $\begin{array}{l}\text { Anterior, } \\
\text { bilateral }\end{array}$ & + & OPG, CBCT, MRI & I + & 0 & - & $\begin{array}{l}\text { Increase in } \\
\text { size }(12 \mathrm{ys})\end{array}$ & $\begin{array}{l}\text { On MRI, bone defect is } \\
\text { filled in with salivary } \\
\text { gland tissue }\end{array}$ \\
\hline
\end{tabular}

${ }^{1}$ Age: The age information relates to the date of radiological examinations. ${ }^{2}$ Inferior border of LMBD: $0=$ Lower border of LMBD distinct from basal cortex, $1=$ Superimposition of LMBD and cortex, 2=Vanishing cortical layer below LMBD. ${ }^{3}$ Mandibular canal: $0=$ Lower border of canal distinct from LMBD, 1=Superimposition of LMBD and canal, 2=LMBD lies cranial to upper border of canal. 


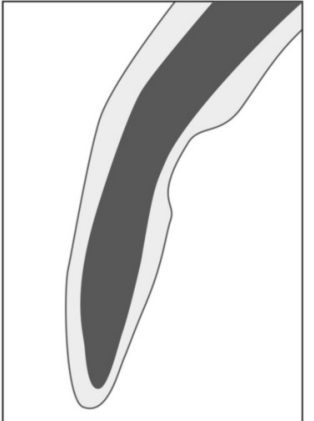

Type 0

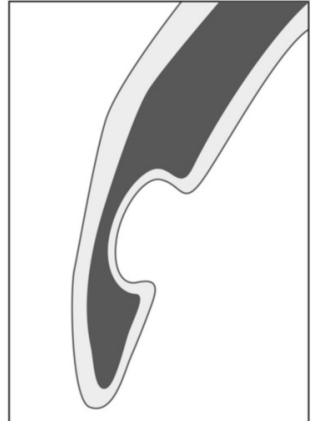

Type I

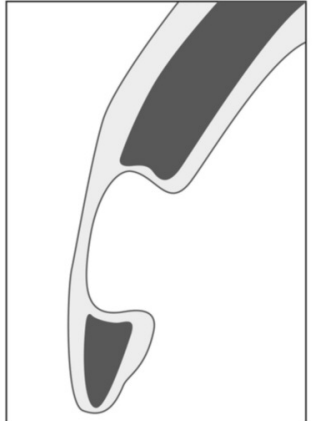

Type II

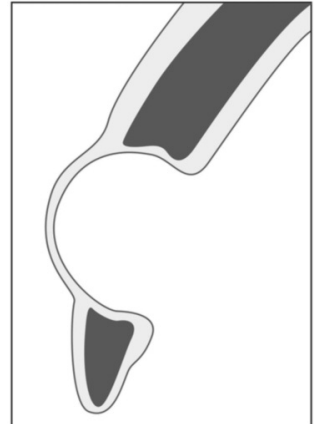

Type III

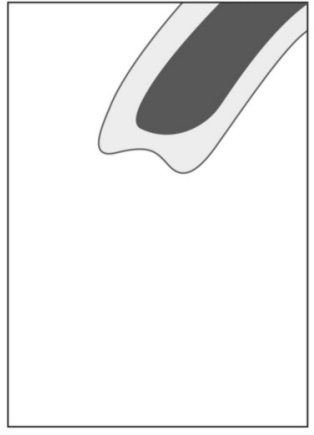

Type IV

Figure 5. Proposal for a classification of lingual mandibular bone depression taking into account the lingual-buccal extent of the lesion. The classification represents an extension of the classification proposed by Ariji et al. (15) and is applicable for cross-sectional images. In addition to the previous radiological descriptions, the current computed radiography techniques should make it possible to identify a lesion limited to the lingual cortex (Type 0). Such early findings are known from anthropological studies (38). Furthermore, the classification should be supplemented by such findings in which the basal cortical is missing in the area of LMBD due to the advanced osteolysis. This finding is rare, but places high demands on the practitioner not to surgically explore the site.

topographical assessment of the lesion by the first descriptor (12). In addition, the current findings and the literature review show that the filling of the lesion by soft tissue such as salivary gland or fat tissue is a common finding of radiologically described or surgically explored lesions (16, 18). However, LMBD is probably a process that originates from the bone leading to resorption and bone remodelling. The optional filling of the lesion in the affected individual very likely depends on the local anatomical conditions. For the rare lesions of the ramus, the ectopic development of adipose tissue should be included in the differential diagnosis. To the best of our knowledge, an expansive lesion of the anterior mandible in childhood and adolescents has so far not been presented in the literature. The asymptomatic thinning of the bones down to the cortex in this case indicates that the static compensation of the mandible tolerates excessive loss of material. The unique case of surgical treatment of a mandibular fracture with the involvement of an ipsilaterally localized dorsal LMBD confirms the assessment of the sufficient compensatory load on residual trajectories in the event of such a bone lesion, because the course of the fracture runs through its marginal area.

Nomenclature. The term 'Stafne's Bone Cavity' and the numerous other terms that have been proposed for these bone findings $(14,16)$ are all based on a systematic analysis of a collection of similar mandibular findings determined on plain radiographs (12). Other osteolytic findings can produce a similar or identical pattern on X-ray images (14). The numerous designations of the developing lingual osseous depression reflect both the historical appreciation of the first descriptor through an eponym (14) and the different theories regarding the pathogenesis of the lesion. The original definition of the entity as being a radiological finding on two dimensional projections has consequences for clinical diagnosis (10). A definition of an entity solely based on radiological images cannot make a statement about the cause of the lesion and the presentation of the finding depends on the resolution capacity of the radiological device in the local application (i.e. projection). While composite terms including the use of the word "cyst" have long been rejected as an obvious misnomer (14), the assessment of the lesion as an unchangeable finding ('static') continues to be terminologically relevant (36). Individual previous reports (37) and the present study indicate that LMBD is not a static cavity. Rather, the findings suggest that clinically (radiologically) noticeable lesions are relatively rapidly developing, that is, bone degradation takes place during a few years until radiological devices display the lesion (Figure 1). In addition, it can be derived from earlier anthropological studies that the growth starts much earlier than plain radiography can record $(32,38)$. Hence the term 'static' also is a misnomer with respect to developmental time of the lesion. Indeed, reports on LMBD highlight the limited growth of the cavity (16). However, the greatest extent of osseous depression on panoramic views has been found in the oldest individuals (39). Furthermore, the largest number of diagnosed lingual bone depressions have been registered in individuals in their middle ages in crosssectional studies $(16,40)$. Reports describing follow-ups are based on the findings of individual observations or a few patients. As there are no population-based long-term followup studies on LMBD, the assumption of a growth arrest after reaching a final size of some centimeter is still not proven. 
Imaging techniques. The most important and most frequently used radiological examination technique for the identification of LMBD is OPG of the jaws $(34,39,41)$. However, this examination technique, which strongly distorts the examination object, has an influence on the detection rate of the lesions in the different jaw sections. The limited information about the anterior mandible, especially in the basal sections, make OPG far less useful for identifying anterior LMBD compared to more posterior lesions (24). It is likely that in studies performed with OPG, the more anterior LMBD are underrepresented. A similar assessment also applies to anterior buccal mandibular depressions (42). Current reviews (34) and the results of our own examination testify that the radiological diagnosis of LMBD should be made using a cross-sectional imaging technique that shows the bones in detail. In cases of doubt, MRI is indicated to characterize the soft tissue of the region of interest in order to support the decision between a wait-and-see policy and surgical exploration.

Anthropological studies. Anthropological studies of skull collections have shown that the development of lingual mandibular depression clearly precedes radiological detectability $(34,38)$. However, studies on this material have come to the conclusion that LMBD is not a finding of the child's or adolescent's lower jaw (32). Indeed, reports of childhood LMBD are very rare and provide no evidence of a pathogenesis that could be distinguished from that in adults. The number of jaw lesions is higher in anthropological studies than on the study of OPGs (38). Tooth roots can reach into the cavity (43).

Age and gender. Summary presentations on the age distribution of patients with LMBD confirm the predominance of male individuals between the ages of 40 and 70 (16), but do not correspond to the mean life expectancy of the examined population.

\section{Localization of $L M B D$}

Posterior $L M B D$. The posterior variant of the LMBD is the most common form of the lesion. Difficulties in diagnosis can arise if larger lesions relate to the nerve canal and the tips of the roots.

Anterior $L M B D$. In particular large anterior LMBDs can present considerable differential diagnostic difficulties because numerous benign and malignant lesions can develop this osseous phenotype on standard radiographs (44). Similar to posterior LMBD, the relationship of the lesion to the tooth roots and the nerve canal in the anterior variant is determined by the lesion's origin and size (45). Additional imaging techniques are therefore recommended in these cases and surgical exploration is rated indispensable in individual cases

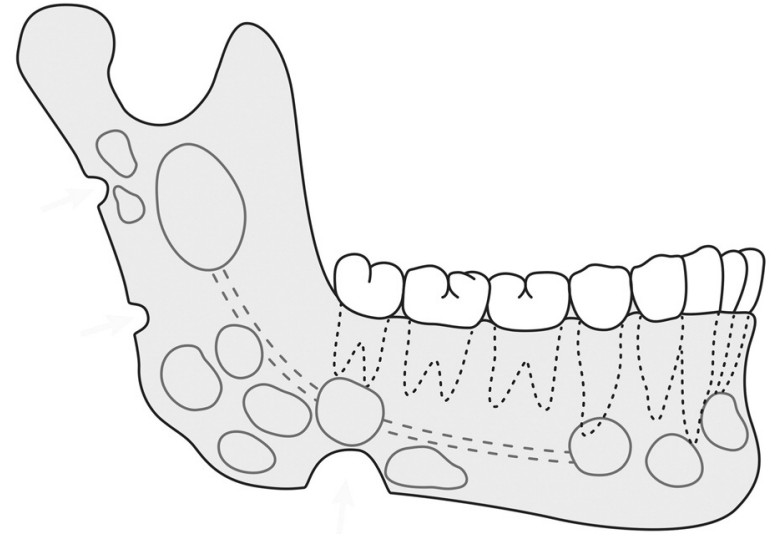

Figure 6. Lateral view of the lower jaw showing the predilection sites of lingual mandibular bone defects (LMBD) on radiographs. The drawing is based on the schematic representation of an earlier review on the $L M B D$ (16) and takes into account recent evaluations (34). In principle, in all corpus regions, the lesions that are predominantly arising basally in the lower jaw can reach the area of the alveolar process and thus simulate odontogenic lesions. The limitation of the lesion is intended to illustrate the main distributions of the LMBD. A cortical border of the LMBD is more common in dorsal locations (16). Cortical defects of the condyle and coronoid so far have not been associated with LMBD. Lesions with an interruption of the basal and dorsal edge of the bone extend beyond the topography assigned in the term "lingual mandibular bone depression".

$(44,45)$. A representative tissue sample with sufficient exposure of the site is recommended to avoid extensive resections in the case of anterior LMBD (46).

LMBD of mandibular ramus. Bone depression of the ramus is considered the rarest variant. An earlier evaluation of the published cases on the LMBD (16) showed that ramus LMBD corresponded to $2.43 \%$ of the total collection of LMBD. Close topographical relationship to salivary glands was also emphasized for LMBD in this location. However, the initial reports failed to provide clear evidence of salivary gland tissue in the lesion (21). In the presented case, the most probable diagnosis was the assessment of the lesion as fatty tissue or tissue with lymphatic components. Ramus defects are described as predominantly round (16). The case shows ovoid shape (Figure 2). Ovoid shape distinguishes LMBD at this site from LMBD of the mandibular angle and corpus on archaeological samples (47). Figure 6 shows schematically the predominant sites of LMBD on radiographs.

Progression of $L M B D$. The delimitation of a radiologically identified lesion of the LMBD type on OPG from similar lesions takes into account the frequency of the lesion in relation to age, gender and growth characteristics. However, the growth of the lesion can only be assessed as in relation to time, so in 


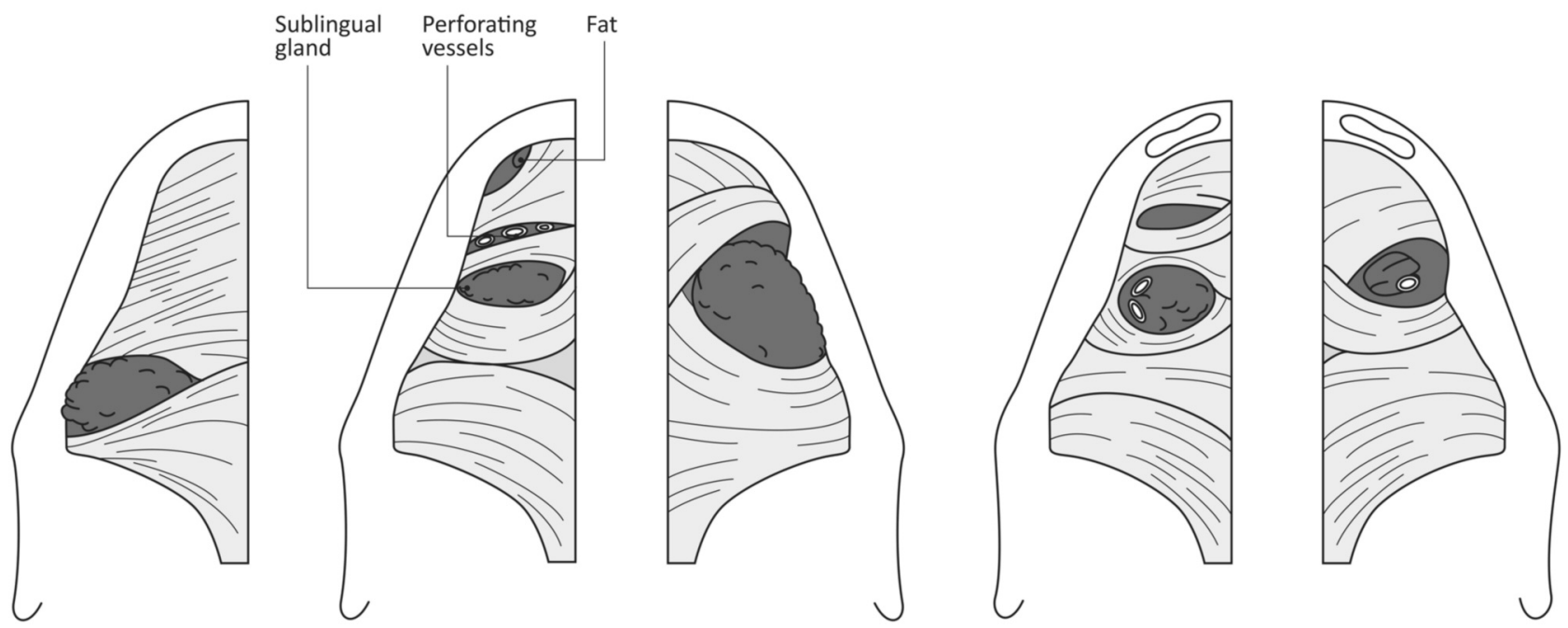

Figure 7. Schematic representation of the herniation of salivary glands and fatty tissue between the mandible and mylohyoid muscle according to Gaughran (49). The investigations were originally intended to illustrate the different ways in which malignant tumors of the mouth floor can infiltrate in the neck depending on the variable anatomy. The individually variable, mostly one-sided findings (herniations) were collected in 117 of 324 cadaver half-heads. The individual variation of the localization and the dehiscence size are considerable, as is the content that penetrates through the 'mylohyoid boutonnière' (49).

the initial diagnosis the risk remains of accepting a developmental disorder where a neoplasia has developed (48). Reviews of LMBD have clearly shown that the lesion can arise in many parts of the lower jaw (Figure 6) (16, 34). Radiological imaging in different dimensions is highly recommended for better diagnosis (15). The general assessment of LMBD as a growth-limited lesion is well justified by many studies (34). However, original reports are usually describing single cases or present a summary of a few cases in advanced age. However, the growth capacity of the previous case of anterior LMBD in an adolescent has so far been unusually extensive and the final size cannot yet be estimated.

Pathogenesis of $L M B D$. The explanation for the cause of the osseous lesion originally described by Stafne was an innate differentiation disorder of the lower jaw (12). This assumption was rejected early on with the indication that the lesion had not yet been diagnosed in children and that considerable time is required for the apparently postnatal development (37).

There are several theories concerning the pathogenesis of the lesion. The explanation favored by most authors is a process of bone resorption caused by external pressure from the neighboring salivary glands (16). It is postulated that the lesion is gradually filled with salivary gland tissue during consecutive phases of progressive bone resorption (16). In particular, the detection of inflammatory processes within the ectopic salivary gland tissue is cited by some authors as a compelling reason for the 'glandular hypothesis' of LMBD (16).
However, other investigators oppose to the hypothesis of a causal connection between the lesion and the salivary glands (15). In particular, the pressure exerted by salivary glands on the neighboring bones is difficult to understand. In fact, dehiscences of the muscles and fascia of the mouth floor are relatively common, but individually very variable (Figure 7). Such interruptions in the segmentation of the mouth floor favor narrowing of the space between the bones and salivary glands, but also between fatty tissue and bones (49) (Figure 7). However, a dehiscence of a muscle should relieve the capsular tension of the salivary gland rather than promoting an increase in the capsule pressure on the bones.

Ariji et al. have examined 15 patients with posterior LMBD using CT and sialography (15) (Figure 8). They confirmed the filling of the cavity with salivary gland tissue in larger defects. However, the authors emphasized that there were clear LMBDs in which no salivary gland tissue could be detected and exclude the position of the submandibular gland relates to the lingual mandible as the only cause of the development of the cavity. They suspected that a number of different factors must coincide to produce the phenotype. The authors indicated that similar findings can also arise on the buccal surface of the mandible (50) and thus distant to salivary gland tissue (15).

Vascular changes, especially of the inferior alveolar artery, can be counted among the factors that favor a local perfusion disorder with bone depression (32, 51-55). To our knowledge, however, there are no angiographic or morphological studies of the local vascular status in LMBD. 

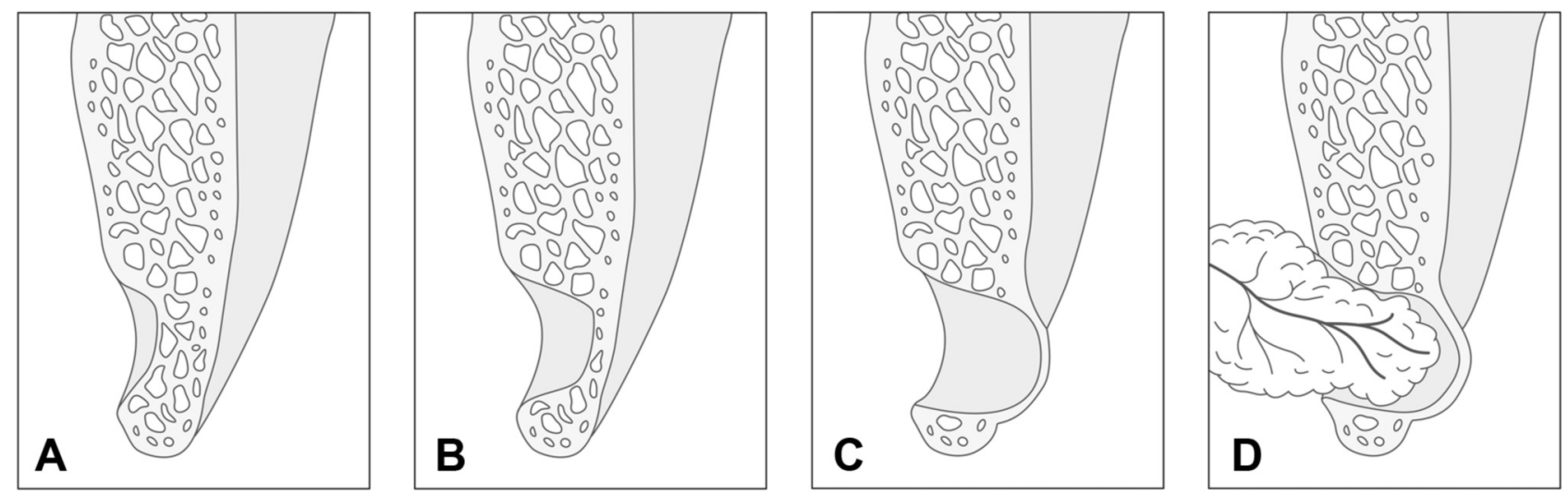

Figure 8. Schematic representation of the mandible in the area of the jaw angle, transverse bone section. The illustration follows the stages of LMBD development as described by Ariji et al. (15), only slightly modified. The first phase of the lesion is characterized by a slight indentation of the lingual, intact cortex (A). In further steps there is extensive resorption of bone (B and C). According to the description of Ariji et al. (15), the pathogenesis of $L M B D$ in this phase of remodeling means that the cavity is not filled with soft tissue. It is only in the terminal step that the salivary gland tissue prolapses into the $L M B D(D)$. It is therefore the case-by-case coincidence of two pathogenetically independent findings.

Classification. Classifications of the extent of the LMBD serve to objectify assessments of the presumed change in shape, support the differentiation of the developmental lesion from tumors and clarify the relationship between the contour of the lesion and the potential content. For classification, imaging in three dimensions is preferable to plain radiography. A very clear and easy to use classification is based essentially on the assessment of the buccal cortex (15) (Figure 5). The lesion can either be a lingual impression and thinning of the cancellous bone (Type I) with complete resorption of the bone without changing the buccal cortex (Type II) or can additionally cause a buccal bulging of the thinned buccal cortex (Type III). This classification correctly describes the predominant number of radiologically conspicuous cases, but it can be assumed that the rapidly growing use of $\mathrm{CBCT}$ in dental and maxillofacial diagnostics will make it possible to detect early phases of bone resorption (Figure 5, Type 0). Indeed, histological findings show that the thinned lingual cortex can be slightly indented into the mandibular body during initial cortical resorption and the lesion is in direct contact with the nerve canal, so depression without loss of cancellous bone can be a stage in the development of LMBD (38). Furthermore, single observations have described complete loss of basal bone in LMBD (33). This rare finding can be classified as Type IV (Figure 5).

Differential diagnosis. The differential diagnosis of osteolytic lesion of the jaw angle includes numerous entities. Three-dimensional representations of the region of interest can decisively contribute to diagnosis in many cases. However, recent evaluations of the literature show that a LMBD can arise in almost all sections of the mandible, with the exception of the articular process (34). It was concluded that LMBD has to be differentially diagnosed from every other osteolysis detected on OPG (34). The following examples are intended to illustrate the capacities and limitations of radiological differential diagnosis in LMBD. The presentation is necessarily case-by-case and anecdotal.

1. A 72-year old male with history of Kaposi sarcoma, negative for HIV infection. The patient had developed a cervical-occipital lesion of unclear biological characteristics that imaging of the head and neck region was required. On MRI, a contrast-enhancing lesion of the lower jaw on the left side in the molar area was noticed. The lesion had a perifocal edema. CBCT showed a solid lesion with bicortical limitation. A developmental disorder with lingual depression of the bone was excluded (Figure 9A-C). What was striking in the three-dimensional reconstruction of the bone surface was the rough bone surface of the lingual cortex that lies exactly in the area of the lesion. During the surgical procedure, a vestibular fenestration of the cortex was performed underneath the molars and the cystic mass was removed. Histologically, ossifying fibroma was diagnosed.

2. A 49-year-old male patient with known multiple myeloma. An OPG was performed to initiate dental treatment before planned chemotherapy (Figure 9D). OPG showed several osteolytic lesions without marginal sclerosis. The distribution pattern of the lesions was similar to the predilection sites of LMBD. The sites of metastatic multiple myeloma in the mandible were undoubtedly very diverse (56). However, similar locations of lesions to those visible here have already been described (57-59). The vascular contribution to LMBD has already been discussed in previous studies with reference 

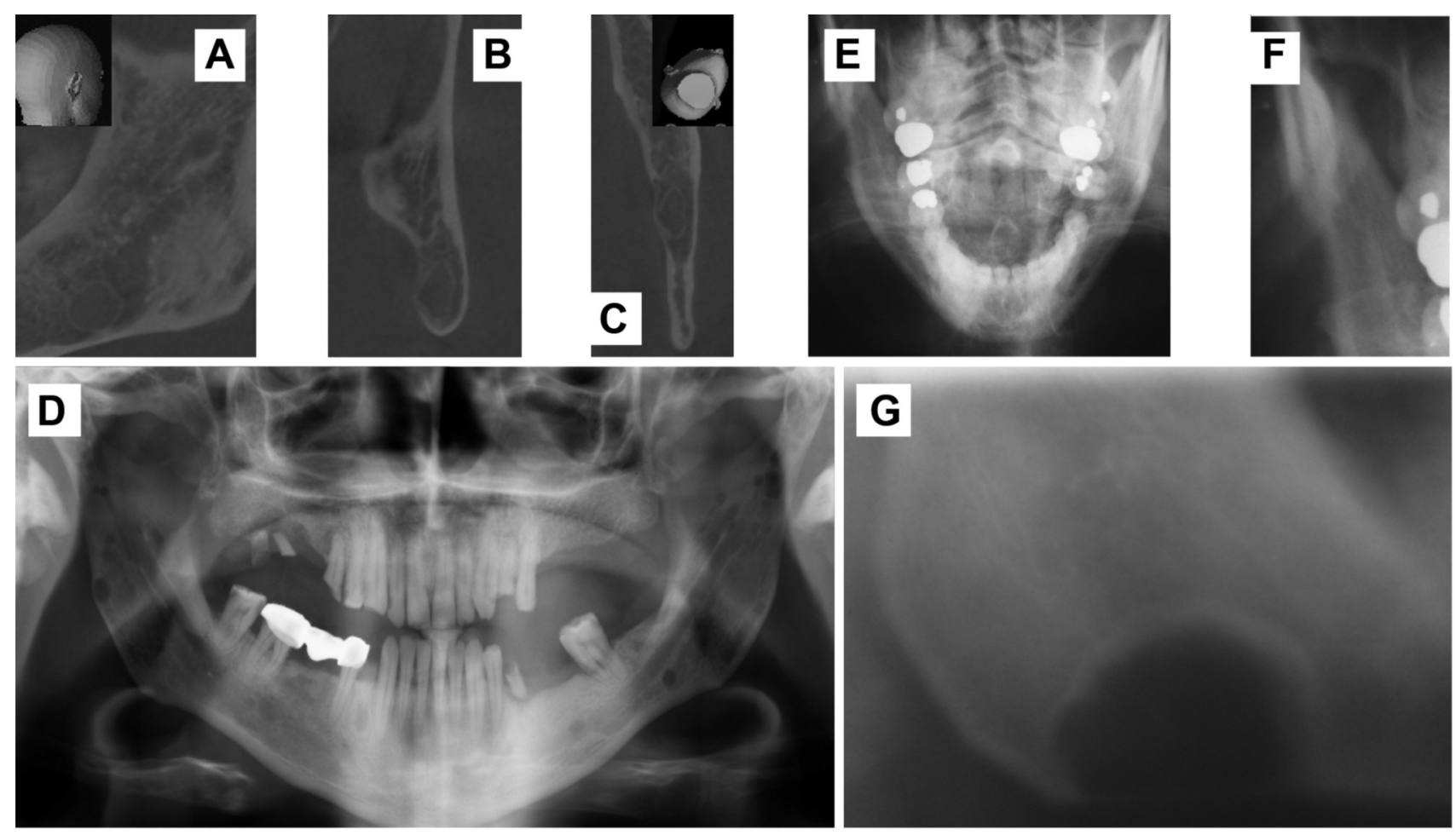

Figure 9. Details of a cone beam computed tomogram (CBCT) of a patient with ossifying fibroma $(A-C)(A=$ sagittal, $B=$ coronal, $C=$ axial $)$, an orthopantomogram $(O P G)$ of a patient with multiple myeloma $(D)$, and cropped image of posterior-anterior radiographs $(E, F)$ and tomography $(G)$ of a patient with buccal posterior mandibular bone depression $(E-G)$. A-C: The normal shape and intact cortex of the lower jaw angle was only visible using CBCT, so that the suspected diagnosis of an LMBD was rejected. Surgical exploration revealed a cyst-like cavity filled with tumor. D: Numerous small radiotranslucent lesions are visible on the OPG. The sharply defined lesions do not have a sclerosed margin. The distribution pattern of the intramedullary lesions on OPG is reminiscent of the predilection sites of LMBD (Figure 6). E-G: Incidental finding of posterior buccal depression of the mandible. The lesion is shown on the tomogram in outline, internal structure and localization, which, without additional information, does not allow differentiation from $L M B D$.

to the early onset atherosclerosis of the inferior alveolar artery and the suspected perfusion disorder in bone regions peripheral to the central artery (51-55).

3. A 58-year-old, asymptomatic male patient with a coincidental finding of buccal bone depression in the area of the right angle of the jaw (Figure 9E and F). Conventional tomography showed a lesion similar to LMBD (Figure 9G). Lesions of this type are extraordinarily rarely reported $(50,60)$.

4. A 14-year old male patient with known neurofibromatosis type 1 (NF1) who developed a congenital hemifacial, left sided plexiform neurofibroma. The patient's OPG showed the typical deformation of the facial skull, especially the lower jaw (Figure 10), as described for extensive facial PNF (11). What is unusual about this bone finding is the basal, bicortical perforating osteolysis of the mandible in the area of the jaw angle. In NF1-associated facial PNF, the infiltration and destruction of peri-mandibular soft tissues are associated with a general deformation of the affected mandibular side. Enlargements of the foramina are interpreted as a tumor manifestation. The basal defect of this patient resembles an advanced, bicortical mandibular depression. Bone narrowing, loss of jaw angle and resorption of the ramus are known, rare findings in NF1 and are associated with PNF (35). However, central bone loss of the jaw angle is very rare in NF1. An analysis of OPGs from patients with NF1 had identified only one case with LMBD but no bicortical bone erosion. In this reported case, the lesion was filled with soft tissue that was isointense and in continuity with the lingually adjacent salivary gland (35).

Surgery. There is general consensus that LMBD does not require surgical treatment $(16,34)$. The clinical significance of LMBD is primarily the differential diagnosis of LMBD to entities that look similar in imaging. Localization (below the nerve canal), size limitation of the lesion as well as the apparent constancy of the lesion in terms of area or volume ('static') during the years of observation are crucial parameters to decide against exploration (16). In one of the cases 

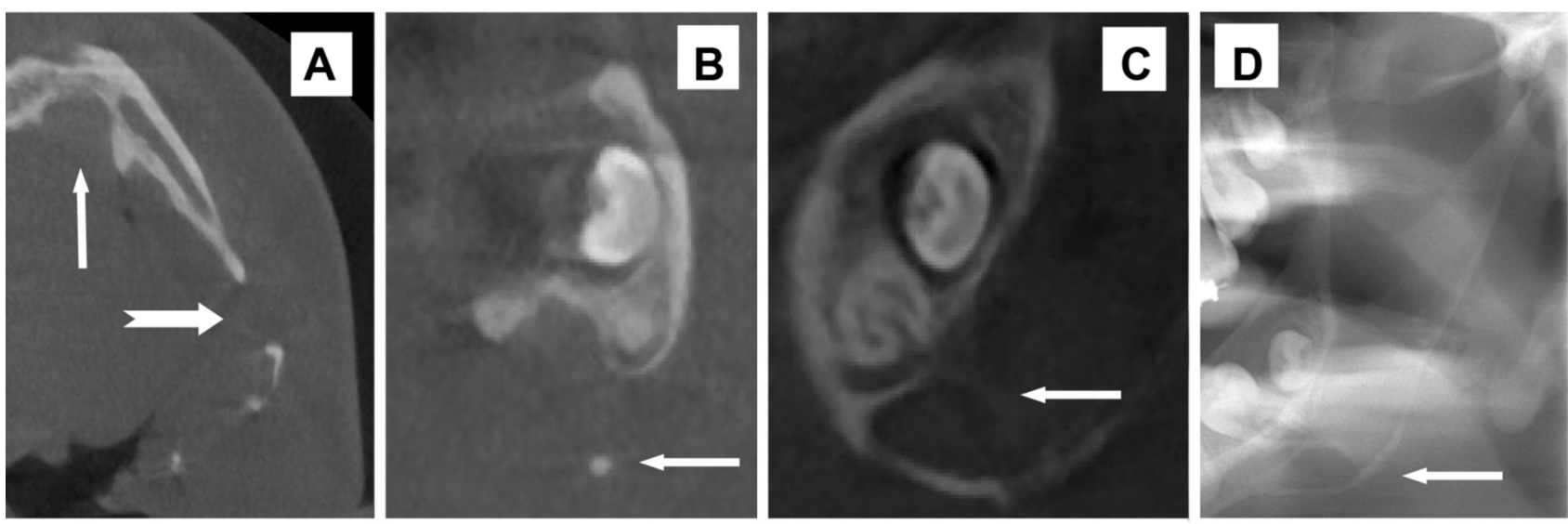

Figure 10. Patient with neurofibromatosis type 1 and diffuse hemifacial plexiform neurofibroma (PNF) of the left facial side. Cropped images of cone beam tomograms $(A-C)$ and orthopantomogram $(O P G)$ illustrating a mandibular lesion similar to a lingual mandibular bone depression. A. axial section of left lower jaw shows a basal, bicortical defect (horizontal arrow). Note ipsilateral anterior lingual bone depression of mandible (vertical arrow). B. Detail of coronal section shows lower margin of the bone lesion is an extremely thinned cortical bony bridge (arrow). C. Detail of sagittal section shows a thinned bone forming the cranial part of the lesion (arrow). D. On OPG, the lesion is hardly distinguishable from a lingual mandibular bone depression (arrow). However, deformation of the mandibular corpus and ramus are characteristic of bone changes in patients with diffuse facial PNF (35). The examination of the soft tissues that had grown around the retained, incompletely developed molar, as well as a tissue sample of the bone defect were diagnosed as neurofibroma.

presented here, surgical exploration was chosen due to the unusually rapid growth of the lesion. The findings showed only connective tissue with no evidence of epithelial parenchyma. Surgical exploration has been repeatedly indicated because imaging was considered insufficient for the assessment of the bone's biological characteristics $(46,61)$. The exploration and confirmation of the diagnosis of a developmental disorder using representative biopsies of the lesion can prevent extensive resections (46). In the presented case there was no mental nerve disorder that could have been taken as an indication of compression or invasion due to the growth of the lesion (62). On the other hand, the lack of bony separation between the LMBD and the nerve canal can be associated with paraesthesia of the lip without prior surgical exploration (63). Therefore, increased caution is required for planned interventions in order to avoid nerve damage. Indeed, it still applies that the detection of ectopic salivary gland tissue on adequate images sufficiently secures the diagnosis of LMBD (35) and consequently surgical exploration usually is not necessary in the majority of cases (49).

The quality of surgical exploration in cases of LMBD has been criticized and repeatedly used to explain the lack of salivary gland tissue in the biopsy as a result of unsuccessful exploration of the poorly visible site. This argument was refuted by photo documentation of the opened site (33), and by detailed imaging of the soft tissue content of the cavity (15).

Preventing a pathological fracture is another reason for surgical intervention in case of LMBD. This measure has so far been used only rarely according to published reports (64). Indeed, it is known from a single report that a mandibular fracture occurred after osteotomy of a wisdom tooth. LMBD was situated caudally to the retained tooth (65). The present analysis shows that in patients with LMBD, a fracture line runs through the lesion. In this case, no surgical measure has had an impact on the bone's trabecular system prior to the trauma. What is striking in this case is the slight deflection of the fracture line where it hits the lesion. The fracture line starts from the dorsal ramus and inferior to the condyle and runs through the ramus in straight caudal direction. However, the fracture does not pass through the most thinned region of the lesion, but at its base. It is plausible to assume that the strengthening of the bone in the edge area of the cavity caused a slight distraction of the course of the fracture (Figure 3 ). The compaction of the bone of LMBD is often indicated in plain and cross-sectional X-ray image as 'sclerosis' and a sign that it is a benign, probably a lesion with self-limiting growth (16).

\section{Conclusion}

Lingual mandibular bone depression (LMBD) is a poorly understood benign developmental disorder which, however, needs to be diagnosed properly and to be differentiated from other lesions that require specific therapy. The data of the present study and other recently presented studies indicate that the lesion can occur in almost the entire lower jaw and must therefore be taken into account in a large number of radiological findings. The lesion shows both growth spurts, 
which brings it to radiological visibility in plain radiography, as well as much longer-lasting growth phases, as seen in a case of the anterior LMBD presented here. The threedimensional radiological representation of the lesion should, whenever possible, supplement the usually incidental identification of LMBD on plain radiographs.

\section{Conflicts of Interest}

The Authors have no conflicts of interest with regard to the work presented.

\section{Authors' Contributions}

REF, EB, TV and MG treated the patients, REF, FKK, TV, US and MG researched the literature and drafted the article. CH and JZ performed morphological studies on the tissue specimen. All Authors gave final approval for publication.

\section{Acknowledgements}

This research did not receive any specific grant from funding agencies in the public, commercial, or not-for-profit sectors.

\section{References}

1 Matsuda S, Yoshimura H, Yoshida H, Taga M, Imamura Y, Kiyoshima $\mathrm{T}$ and Sano K: Ossifying fibroma in the mandibular angle mimicking metastatic clear cell renal cell carcinoma: A case report. Medicine (Baltimore) 98: e16595, 2019. PMID: 31415350. DOI: 10.1097/MD.0000000000016595

2 Parvizi F and Rout PG: An ossifying fibroma presenting as Stafne's idiopathic bone cavity. Dentomaxillofac Radiol 26: 361363, 1997. PMID: 9482014. DOI: 10.1038/sj.dmfr.4600294

3 Aoki EM, Abdala-Júnior R, Nagano CP, Mendes EB, Oliveira JX, Lourenço S and Arita ES: Simple bone cyst mimicking Stafne bone defect. J Craniofac Surg 29: e570-e571, 2018. PMID: 29742571. DOI: 10.1097/SCS.0000000000004590

4 Atil F, Adisen MZ, Misirlioglu M and Suer BT: Stafne bone cavity complicated by periapical infection. J Coll Physicians Surg Pak 26: 109-110, 2016. PMID: 28666498.

5 da Silva WG, Kemp AT, Dos Santos-Silva AR, Diz MDP and Brandão TB: Stafne's bone defect in a metastatic prostate cancer patient: A diagnostic conundrum. J Clin Exp Dent 10: e88-e91, 2018. PMID: 29670722. DOI: 10.4317/jced.53656

6 Lewandowski B, Brodowski R, Pakla P, Stopyra W and Gawron I: Leiomyosarcoma in the mandible: A rare case report. Medicine (Baltimore) 95: e4011, 2016. PMID: 27399080. DOI: 10.1097/MD.0000000000004011

7 Adachi M, Inagaki T, Ehara Y, Azuma M, Kurenuma A, Motohashi M and Muramatsu Y: Primary intraosseous carcinoma arising from an odontogenic cyst: A case report. Oncol Lett 8 : 1265-1268, 2014. PMID: 25120703. DOI: 10.3892/ol.2014.2248

8 Bansal S, Desai RS, Shirsat P, Prasad P, Karjodkar F and Andrade $\mathrm{N}$ : The occurrence and pattern of ameloblastoma in children and adolescents: an Indian institutional study of 41 years and review of the literature. Int J Oral Maxillofac Surg 44: 725-731, 2015. PMID: 25655766. DOI: 10.1016/j.ijom.2015.01.002
9 Martínez-Madrigal F, Pineda-Daboin K, Casiraghi O and Luna MA: Salivary gland tumors of the mandible. Ann Diagn Pathol 4: 347353, 2000. PMID: 11149964. DOI: 10.1053/adpa.2000.19395

10 Marx RE and Stern D: Conditions of Developmental Disturbances. In: Marx/Stern: Oral and Maxillofacial Pathology. Quintessence, Carol Steam, Ill., 2003, pp. 207-213.

11 Friedrich RE and Scheuer HA: Unilateral creeping destruction of deformed mandibular ramus and angle associated with extensive facial plexiform neurofibroma in neurofibromatosis type 1: A case report with analysis of the literature for diagnosing osteolytic events of the mandible in tumor-suppressor gene syndrome. Anticancer Res 38: 4083-4091, 2018. PMID: 29970534. DOI: 10.21873/anticanres.12698.

12 Stafne E: Bone cavities situated near the angle of the mandible. J Am Dent Assoc 29: 1969-1972, 1942.

13 Shafer WG, Hine MK and Levy BM: A Textbook of Oral Pathology. 4th edition, Saunders, Philadelphia, pp. 35-37, 1983.

14 Reichart PA and Philipsen HP: Odontogenic Tumors and Allied Lesions, Quintessence Publ., London, pp. 351-358, 2004.

15 Ariji E, Fujiwara N, Tabata O, Nakayama E, Kanda S, Shiratsuchi Y and Oka M: Stafne's bone cavity. Classification based on outline and content determined by computed tomography. Oral Surg Oral Med Oral Pathol 76: 375-380, 1993. PMID: 8378054. DOI: 10.1016/0030-4220(93)90271-5

16 Philipsen HP, Takata T, Reichart PA, Sato S and Suei Y: Lingual and buccal mandibular bone depressions: a review based on 583 cases from a world-wide literature survey, including 69 new cases from Japan. Dentomaxillofac Radiol 31: 281-290, 2002. PMID: 12203126. DOI: 10.1038/sj.dmfr.4600718

17 Assaf AT, Solaty M, Zrnc TA, Fuhrmann AW, Scheuer H, Heiland M and Friedrich RE: Prevalence of Stafne's bone cavity - retrospective analysis of 14,005 panoramic views. In Vivo 28: 1159-1164, 2014. PMID: 25398816.

18 Hisatomi M, Munhoz L, Asaumi J and Arita ES: Stafne bone defects radiographic features in panoramic radiographs: Assessment of 91 cases. Med Oral Patol Oral Cir Bucal 24: e12e19, 2019. PMID: 30573717. DOI: 10.4317/medoral.22592

19 Schneider T, Filo K, Locher MC, Gander T, Metzler P, Grätz KW, Kruse AL and Lübbers HT: Stafne bone cavities: systematic algorithm for diagnosis derived from retrospective data over a 5-year period. Br J Oral Maxillofac Surg 52: 369-374, 2014. PMID: 24560588. DOI: 10.1016/j.bjoms.2014.01.017

20 Wolf J: Bone defects in mandibular ramus resembling developmental bone cavity (Stafne). Proc Finn Dent Soc 81: 215-221, 1985. PMID: 4080685.

21 Barker GR: A radiolucency of the ascending ramus of the mandible associated with invested parotid salivary gland material and analogous with a Stafne bone cavity. Br J Oral Maxillofac Surg 26: 81-84, 1988. PMID: 3422827. DOI: 10.1016/0266-4356(88)90155-6

22 Sisman Y, Miloglu O, Sekerci AE, Yilmaz AB, Demirtas O and Tokmak TT: Radiographic evaluation on prevalence of Stafne bone defect: a study from two centres in Turkey. Dentomaxillofac Radiol 41: 152-158, 2012. PMID: 22074869. DOI: $10.1259 / \mathrm{dmfr} / 10586700$.

23 Hisatomi M, Munhoz L, Asaumi J and Arita ES: Parotid mandibular bone defect: A case report emphasizing imaging features in plain radiographs and magnetic resonance imaging. Imaging Sci Dent 47: 269-273, 2017. PMID: 29279827. DOI: 10.5624/isd.2017.47.4.269. 
24 Friedrich RE, Scheuer HA and Gröbe A: Anterior lingual mandibular bone depression in an 11-year-old child. In Vivo 26: 1103-1107, 2012. PMID: 23160701.

25 Aguiar LB, Neves FS, Bastos LC, Crusoé-Rebello I, Ambrosano GM and Campos PS: Multiple stafne bone defects: a rare entity. ISRN Dent 2011: 792145, 2011. PMID: 21991486. DOI: 10.5402/2011/792145

26 Etöz M, Etöz OA, Sahman H, Sekerci AE and Polat HB: An unusual case of multilocular Stafne bone cavity. Dentomaxillofac Radiol 41: 75-78, 2012. PMID: 22184629. DOI: 10.1259/dmfr/ 34731967

27 Boffano P, Gallesio C, Daniele D and Roccia F: An unusual trilobate Stafne bone cavity. Surg Radiol Anat 35: 351-353, 2013. PMID: 23187427. DOI: 10.1007/s00276-012-1043-7

28 Campos PS, Panella J, Crusoé-Rebello IM, Azevedo RA, Pena $\mathrm{N}$ and Cunha T: Mandibular ramus-related Stafne's bone cavity. Dentomaxillofac Radiol 33: 63-66, 2004. PMID: 15140825. DOI: $10.1259 / \mathrm{dmfr} / 39682286$

29 Schneider T, Filo K, Stadlinger B, Locher M, Kruse AL, Lübbers HT: Eine ungewöhnliche Stafne-Kavität. Mehrkammerige Knochenläsion mit bukkaler auftreibung. Ein Fallbericht. [An atypical Stafne cavity-multi-chamber bone lesion with bucal expansion. A case report]. Swiss Dent J 124: 545-555, 2014. PMID: 24853338.

30 Karmiol M and Walsh RF: Incidence of static bone defect of the mandible. Oral Surg Oral Med Oral Pathol 26: 225-228, 1968. PMID: 5242054. DOI: 10.1016/0030-4220(68)90259-4

31 Correll RW, Jensen JL and Rhyne RR: Lingual cortical mandibular defects: a radiographic incidence study. Oral Surg Oral Med Oral Pathol 50: 287-291, 1980. PMID: 6932004. DOI: 10.1016/0030-4220(80)90386-2

32 Kay LW: Some anthropologic investigations of interest to oral surgeons. Int J Oral Surg 3: 363-379, 1974. PMID: 4217312. DOI: $10.1016 / \mathrm{s} 0300-9785(74) 80001-3$

33 Friedrich RE, Zustin J, Scheuer HA, Assaf AT and Gröbe A: An unilateral basal bone defect of the mandible occupied by fatty tissue: Stafne's cavity. In Vivo 26: 1045-1048, 2012. PMID: 23160691 .

34 Aps JKM, Koelmeyer N, Yaqub C: Stafne's bone cyst revisited and renamed: the benign mandibular concavity. Dentomaxillofac Radiol 20190475, 2020. PMID: 31944858. DOI: 10.1259/dmfr. 20190475

35 Friedrich RE and Scheuer HT: Non-odontogenic intraosseous radiolucent lesions of the mandibular body are rare findings on panoramic views of patients with neurofibromatosis type 1 . Anticancer Res 39: 1971-1985, 2019. PMID: 30952741. DOI: 10.21873/anticanres. 13308

36 Nishimura S, Osawa K, Tanaka T, Imamura Y, Kokuryo S, Habu M, Jyoujima T, Miyamura Y, Mochida KI, Inoue T, Kito S, Wakasugi-Sato N, Matsumoto-Takeda S, Oda M, Yoshiga D, Kodama M, Sasaguri M, Tominaga K, Yoshioka I and Morimoto Y: Multiple mandibular static bone depressions attached to the three major salivary glands. Oral Radiol 34: 277-280, 2018. PMID: 30484032. DOI: 10.1007/s11282-017-0304-x

37 Tolman DE and Stafne EC: Developmental bone defects of the mandible. Oral Surg Oral Med Oral Pathol 24: 488-490, 1967. PMID: 5233828. DOI: 10.1016/0030-4220(67)90423-9

38 Harvey W, Noble HW: Defects on the lngual surface of the mandible near the angle. Br J Oral Surg 6: 75-83, 1968. PMID: 5246825. DOI: $10.1016 / \mathrm{s} 0007-117 x(68) 80001-0$
39 Oikarinen VJ and Julku M: An orthopantomographic study of developmental mandibular bone defects (Stafne's idiopathic bone cavities). Int J Oral Surg 3: 71-76, 1974. PMID: 4209181. DOI: $10.1016 / \mathrm{s} 0300-9785(74) 80082-7$

40 Adisen MZ, Yilmaz S, Misirlioglu M and Atil F: Evaluation of volumetric measurements on $\mathrm{CBCT}$ images using stafne bone cavities as an example. Med Oral Patol Oral Cir Bucal 20: e580e586, 2015. PMID: 26116844. DOI: 10.4317/medoral.20633

41 Uemura S, Fujishita M, Fuchihata H. Radiographic interpretation of so-called developmental defect of mandible. Oral Surg Oral Med Oral Pathol 41: 120-128, 1976. PMID: 1061031. DOI: 10.1016/0030-4220(76)90261-9

42 Buchner A, Carpenter WM, Merrell PW and Leider AS: Anterior lingual mandibular salivary gland defect. Evaluation of twentyfour cases. Oral Surg Oral Med Oral Pathol 71: 131-136, 1991. PMID: 2003004. DOI: 10.1016/0030-4220(91)90452-i

43 Jordana X, García Sívoli C, Galtés I, Palacios M, Cos M and Malgosa A: Report on a Stafne defect in a man from medieval age. J Oral Maxillofac Surg 65: 556-559, 2007. PMID: 17307608. DOI: 10.1016/j.joms.2005.07.023

44 Turkoglu K and Orhan K: Stafne bone cavity in the anterior mandible. J Craniofac Surg 21: 1769-1775, 2010. PMID: 21119418. DOI: $10.1097 /$ SCS.0b013e3181f40347

45 Voss PJ, Metzger MC, Schulze D, Loeffelbein DJ, Pautke C and Hohlweg-Majert B: Anterior lingual mandibular bone cavity as a diagnostic challenge: two case reports. J Oral Maxillofac Surg 68: 201-204, 2010. PMID: 20006178. DOI: 10.1016/j.joms.2009.03.017

46 Mizuno A, Kawabata T, Nakano Y and Motegi K: Lingual mandibular bone defect - idiopathic bone cavity. Report of a case. Int J Oral Surg 12: 64-68, 1983. PMID: 6406381. DOI: 10.1016/s0300-9785(83)80083-0

47 Mann RW and Shields ED: Cavitation defects on the lingual ramus: a further expression of Stafne's defect. J Craniofac Genet Dev Biol 12: 167-173, 1992. PMID: 1517396.

48 Simpson W: Stafne's mandibular defect containing a pleomorphic adenoma: A report of case. J Oral Surg 23: 553556, 1965. PMID: 14329535.

49 Gaughran GRL: Mylohyoid boutonniére and sublingual buton. J Anat (London) 97: 565-568, 1963. PMID: 14064098.

50 Kocsis GS, Marcsik A and Mann RW: Idiopathic bone cavity on the posterior buccal surface of the mandible. Oral Surg Oral Med Oral Pathol 73: 123-126, 1992. PMID: 1603551. DOI: 10.1016/0030-4220(92)90169-q

51 Bradley JC: Age changes of the inferior alveolar artery. Br J Oral Maxillofac Surg 26: 517-519, 1988. PMID: 3203096. DOI: 10.1016/0266-4356(88)90078-2

52 Bradley JC: The clinical significance of age changes in the vascular supply to the mandible. Int J Oral Surg 10 (Suppl 1): 71-76, 1981. PMID: 6807911.

53 Bradley JC: A radiological investigation into the age changes of the inferior dental artery. Br J Oral Surg 13: 82-90, 1975. PMID: 1056796. DOI: $10.1016 / 0007-117 x(75) 90027-x$

54 Lello GE and Makek M: Stafne's mandibular lingual cortical defect. Discussion of aetiology. J Maxillofac Surg 13: 172-176, 1985. PMID: 3860595. DOI: 10.1016/s0301-0503(85)80042-4

55 Semba I, Funakoshi K and Kitano M: Histomorphometric analysis of age changes in the human inferior alveolar artery. Arch Oral Biol 46: 13-21, 2001. PMID: 11163591. DOI: $10.1016 / \mathrm{s} 0003-9969(00) 00100-\mathrm{x}$ 
56 Lambertenghi-Deliliers G, Bruno E, Cortelezzi A, Fumagalli L and Morosini A: Incidence of jaw lesions in 193 patients with multiple myeloma. Oral Surg Oral Med Oral Pathol 65: 533-537, 1988. PMID: 3163784.

57 Ali IK, Parate AR, Kasat VO and Dora A: Multiple myeloma with primary manifestation in the mandible. Cureus 10: e2265, 2018. PMID: 29732272. DOI: 10.7759/cureus.2265

58 Popovski V, Dvojakovska S, Benedetti A, Panchevski G, Stamatoski A and Janevska V: Mandibular involvement of plasmacytoma - Uncommon case report of rare entity. Ann Med Surg (Lond) 45: 95-97, 2019. PMID: 31440372. DOI: 10.1016/j.amsu.2019.07.021

59 Baykul T, Aydin U, and O Carroll MK: Unusual combination of presenting features in multiple myeloma. Dentomaxillofac Radiol 33: 413-419, 2004. PMID: 15665237.

60 Shields ED: Technical note: Stafne static mandibular bone defect-further expression on the buccal aspect of the ramus. Am J Phys Anthropol 111: 425-427, 2000. PMID: 10685040. DOI: $10.1002 /($ S ICI $) 1096-8644(200003) 111: 3<425:$ : AID AJPA8 $>3.0 . \mathrm{CO} ; 2-8$

61 Richard EL and Ziskind J: Aberrant salivary gland tissue in mandible. Oral Surg Oral Med Oral Pathol 10: 1086-1090, 1957. PMID: 13465121. DOI: 10.1016/0030-4220(57)90059-2
62 Assaf AT, Jürgens TP, Benecke AW, Riecke B, Blessmann M, Zrnc TA, Much CC, Heiland M and Friedrich RE: Numb chin syndrome: a rare and often overlooked symptom. J Oral Facial Pain Headache 28: 80-90, 2014. PMID: 24482791. DOI: 10.11607/jop.994

63 Reuter I: An unusual case of Stafne bone cavity with extraosseous course of the mandibular neurovascular bundle. Dentomaxillofac Radiol 27: 189-191, 1998. PMID: 9693534. DOI: $10.1038 / \mathrm{sj} / \mathrm{dmfr} / 4600349$

64 Prechtl C, Stockmann P, Neukam FW and Schlegel KA: Enlargement of a Stafne cyst as an indication for surgical treatment - A case report. J Craniomaxillofac Surg 41: 270-273, 2013. PMID: 23218505. DOI: 10.1016/j.jcms.2012.10.013

65 Kao YH, Huang IY, Chen CM, Wu CW, Hsu KJ and Chen CM: Late mandibular fracture after lower third molar extraction in a patient with Stafne bone cavity: A case report. J Oral Maxillofac Surg 68: 1698-1700, 2010. PMID: 19939535. DOI: 10.1016/j. joms.2009.06.019. E

Received April 11, 2020

Revised June 19, 2020

Accepted June 20, 2020 